\title{
Home-Based Activities in Support of New Zealand Children's Literacy and Numeracy Skills
}

\author{
Kylie J. Munro ${ }^{1}$, Paul E. Jose ${ }^{1} \&$ Carol S. Huntsinger ${ }^{2}$ \\ ${ }^{1}$ School of Psychology, Victoria University of Wellington, Wellington, New Zealand \\ ${ }^{2}$ Literacy and Elementary Education Department, Northern Illinois University, DeKalb, Illinois, USA \\ Correspondence: Paul E. Jose, School of Psychology, Victoria University of Wellington, P.O. Box 600, \\ Wellington, New Zealand. ORCID identifier: 0000-0002-3104-1871
}

Received: March 12, 2021 Accepted: May 4, $2021 \quad$ Online Published: May 11, 2021

doi:10.5539/jedp.v11n2p17 URL: http://doi.org/10.5539/jedp.v11n2p17

\begin{abstract}
Little is known about the possible benefits of parent-led activities to enable school readiness for New Zealand young children. A two-year longitudinal study of parents and their children (102 4-year-olds and 104 5-year-olds at Time 1) was conducted. Parents completed the Encouragement of Academic Skills in Young Children (EASYC) self-report measure of in-home academic activities, and children's literacy and mathematics achievement were tested initially and one year later. Several parent-led activities were found to predict improved child academic ability across the sampled age range: 1) teaching basic addition and subtraction; and 2) writing and drawing practice.
\end{abstract}

Keywords: young children, parent-led academic enrichment activities, literacy, numeracy, longitudinal study

\section{Literacy and Numeracy Skills}

The transition from preschool education to primary school precipitates a large shift in the child's social, academic and physical environment, and consequently the question of school readiness is raised for individual children. Children who do not adapt well or are unable to fully engage in classroom activities risk long term negative effects, including poorer academic growth (Ladd \& Dinella, 2009), and these outcomes are major concerns of the fields of educational psychology and developmental psychology. The importance of readying young children for formal schooling is underscored by longitudinal research from around the world which has highlighted the importance of children's early numeracy and literacy skills for later academic success (e.g., Claessens, Duncan, \& Engel, 2009; Duncan et al., 2007; Hooper, Roberts, Sideris, Burchinal, \& Zeisel, 2010; Lehrl, Ebert, Blaurock, Rossbach, \& Weinert, 2020; Lonigan, Burgess, \& Anthony, 2000; Pagani, Fitzpatrick, Archambault, \& Janosz, 2010; Romano, Babchishin, Pagani, \& Kohen, 2010). When parents support preschool literacy and numeracy development, children are more likely to be ready to learn the curriculum when they start school.

The present research study of parents' facilitation of their young children's academic skills was based on Vygotsky's Sociocultural Theory, which posits that children's cognitive development is fostered by and co-constructed in social interaction with mentors who are more knowledgeable members of society. The mentors, i.e., individuals who scaffold the child's learning, can be parents, older siblings, peers, or teachers. According to Vygotsky (1978), each child has a zone of proximal development (ZPD), where the lower level represents the skill area in which he or she can perform unassisted (i.e., actual developmental level), and the upper level represents the level of potential development where the child can learn "with adult guidance or in collaboration with more capable peers" (p. 86). Culture influences cognition in that it: provides the tools for mental activity (e.g., language); defines what knowledge is important to learn; formulates the problems to be solved; and develops the kind of logic used. Parents are children's earliest mentors, and in this role, they are typically very sensitive to what knowledge and tools the child possesses and similarly they are usually aware of what the child can readily learn next (Bodrova \& Leong, 1996; Vadeboncoeur \& Dalkili, 2019; Vygotsky, 1978). Accordingly, in our study, we examined which activities parents use to scaffold and guide their children to attain literacy and numeracy knowledge and skills.

\subsection{Early Literacy and Numeracy Development}

Literacy is the capacity to express language through reading and writing. Emergent literacy skills such as letter naming, vocabulary, understanding the function of print, story comprehension, and phonological awareness form 
the foundations of literacy development (e.g., Sénéchal \& LeFevre, 2002; Sonnenschein \& Munsterman, 2002). Mastery of emergent literacy skills is a known indicator for later development in reading and writing at primary school (Lehrl, Smidt, Grosse, \& Richter, 2014; Lonigan et al., 2000).

Mathematics ability at school entry has been identified as the most important predictive factor for future academic achievement (Duncan et al., 2007; Romano et al., 2010). Specifically, in Duncan et al.'s (2007) meta-analysis, early mathematics predicted later mathematics achievement and early literacy predicted later literacy achievement, but early mathematics was a stronger predictor across both domains than was early literacy. Mathematical knowledge is preceded by early numeracy skills such as number naming, counting, and an understanding of quantity (Baroody, 1987), and research illustrates the importance of having a strong foundation in these early numeracy skills in the preschool years. As research demonstrates, skills in early numeracy and literacy are foundational for further development of school-based knowledge and are therefore integral to a child's preschool skillset. With this fact in mind, it is important to understand the role of preschool children's home learning experiences in developing literacy and numeracy skills.

\subsection{Developing Literacy and Numeracy at Home}

Because parents are children's first teachers, young children's literacy and numeracy development is usually initially shaped by parents and families in the home environment. Studies have shown that parents who engage their children in home learning activities improve the literacy and numeracy outcomes for their children (Dulay, Cheung, Reyes, \& McBride, 2019; Griffin \& Morrison, 1997; Huntsinger, Jose, Larson, Krieg, \& Shaligram, 2000). Research using the Home Literacy Model (Sénéchal \& LeFevre, 2002) has demonstrated relationships between the literacy environment at home and children's early literacy skills (Hood, Conlon, \& Andrews, 2008; Skwarchuk, Sowinski, \& LeFevre, 2014). Findings from these several studies have revealed that parents' reports of preschool children's book exposure predicted the development of vocabulary and listening comprehension over time, which, in turn, predicted reading ability in the third year of school.

Using numeracy activities at home has also been shown to improve children's mathematics abilities. Relationships have been found between number-based parent-child activities (such as naming digits, counting, and discussing number values) and the child's mathematics ability (Blevins-Knabe \& Musun-Miller, 1996; Huntsinger, Jose, Liaw, \& Ching, 1997). Similarly, numerical fluency (the ability to perform mathematics problems quickly and efficiently) and math knowledge have been shown to be enhanced through a young child's home-based exposure to formal teaching of number skills and informal numeracy activities (such as number games and everyday applications). More recently, a model for measuring home-based numeracy activities has been developed, which takes a similar approach to the Home Literacy Model (Skwarchuk et al., 2014). Skwarchuk et al.'s findings showed that children's symbolic number knowledge was predicted by engaging in formal teaching activities (such as teaching addition and reciting numbers), and non-symbolic arithmetic was predicted by informal activities (measured through the parent's knowledge of children's board games).

These studies demonstrate that parents can enhance the future academic development of their children by exposing them to early literacy- and numeracy-based activities. It is likely that across different countries and cultures, parents use a variety of activities to promote learning with their children, and these individual activities impact learning in different ways. Sénéchal et al.'s (e.g., 2002, 2008) research has been performed in Canada; Huntsinger et al.'s (1997) work has been performed in the United States and Taiwan; Napoli and Purpura's (2018) work has been performed in the United States; and Aunola et al.'s (2004) research has been performed in Finland. To date, research is lacking on the New Zealand context. It is argued in the present paper that research to determine which activities are most beneficial for the development of children's early numeracy and literacy skills in New Zealand would be of value.

\subsection{The Current Study}

International literature has broadly demonstrated the positive influence of home-based educational activities on young children's numeracy and literacy development. However, research is scant on exactly what activities parents choose to involve their preschool children in as a way to facilitate early academic learning. To address this gap, Huntsinger, Jose, and Luo (2016) created the EASYC (Encouragement of Academic Skills in Young Children) parent self-report measure to capture the range of academic skills-related activities with which parents engage their young children. They documented that the EASYC predicted both numeracy and literacy in preschool American young children, which supports the view that the measure possesses good validity. However, research is lacking on whether the scale performs similarly in other cultural contexts. One exception is that two recent studies (Kara, 2019; Kara \& Çoksoyluer, 2017) have demonstrated the measure's utility in Turkey, but we need demonstrations of its effectiveness in other countries. Thus, the present study's chief contribution to the literature was that we hoped 
to identify activities which are relevant and effective in supporting literacy and numeracy development for preschool children in New Zealand, a Western country similar to the U.S. in many respects but one that is geographically distant from North America.

Activities which have the greatest effect on preparing children for school were expected to be influential not only in the current year of testing, but also predictive of the child's academic skill levels once they had started primary school at ages 5 and 6 years. Thus, 4- and 5-year-old children and their parents were sampled twice, with a year between measurements, to explore the hypothesis that parental use of in-home educational activities would be positively associated with child academic performance concurrently and one year later.

The EASYC measure used in the present study contains both literacy- and numeracy-oriented items, and 1) it was expected that literacy-oriented items (e.g., point out letters and words in the environment) would predict literacy achievement scores more reliably than mathematics achievement scores, and numeracy-oriented items (e.g., practice adding and subtracting single digit numbers) would predict mathematics achievement scores more reliably than literacy achievement scores. Further, we predicted that a factor analysis of the entire measure would yield two factors focused on the two themes of numeracy and literacy. And third, since we used longitudinal data, we also sought to determine whether parental practices at Time 1 would be predictive of greater academic achievement at Time 2 above and beyond the stability of the two measures of academic achievement. We expected that Time 1 parental practices would show benefit in numeracy and literacy scores at Time 2 .

\section{Method}

\subsection{Participants}

A total of 206 children from Wellington, New Zealand (117 boys, 89 girls) and their parents were included at Time 1 in the study. The sample was composed of two almost equal-sized age cohorts (4-year-olds and 5-year-olds) and testing was done at two time points separated by one year. The retention rate from Time 1 to Time 2 was $67.0 \%$.

Cohort 1 consisted of 102 children 4 years of age at Time 1, with $67.6 \%$ of cohort 1 participating at Time 2, when the children were 5 years of age. Cohort 2 was made up of 104 children 5 years of age at Time 1 and $66.3 \%$ participated at Time 2 when they were 6 years old. Parents participated at both time points.

The ethnic make-up of the sample was $92 \%$ European New Zealander and $8 \%$ other (i.e., Māori, Asian New Zealander, and Pacific Nations), so it underrepresented minority New Zealand children while overrepresenting majority New Zealand children.

The dyads of parents and children were recruited from four suburban preschools and primary schools. The determination of social class status was obtained by self-reports from parents concerning their educational level, current occupation, and broad bands of family income. Almost all parents reported obtaining at least an undergraduate degree (92\%), most held professional and semi-professional jobs (e.g., bank tellers, teachers, clerical workers, etc.), and all families earned a middle-class income by New Zealand standards (Labour Market Statistics, 2018).

\subsection{Measures}

Encouragement of Academic Skills in Young Children (EASYC). The EASYC is a 42-item parental self-report measure which seeks to assess the types and frequencies of educational activities in which parents engage with their children at home (Huntsinger et al., 2016). The measure's item selection and development were based on findings obtained in Huntsinger et al.'s (1997, 1998, 2000) longitudinal studies of American children's academic achievement. The study used parent questionnaires, interviews, and videotaped parent-child interactions to determine numeracy- and literacy-based activities parents use with their children during the preschool years. Methods that parents described using at home with their children were captured in open-ended questionnaires and interviews, and these were used to create items for the EASYC. In the current study, parents responded to questions in the EASYC by selecting from options on Likert scales or answering yes/no questions concerning the frequency they incorporated specified learning opportunities into their child's environment. Items address facilitation of literacy (e.g., "encourage our child to complete workbooks that teach proper letter formation") and numeracy (e.g., "practice adding and subtracting single digit numbers"). The complete EASYC measure is provided in the publication by Huntsinger et al. (2016).

Test of Early Mathematics Ability-Second Edition (TEMA-2). The TEMA-2, created by Ginsburg and Baroody (1990), uses 65 questions to assess mathematics knowledge and skills in children ages 3 to 8 years. Both formal (30 items) and informal (35 items) mathematics achievement are measured using a wide range of task types (e.g., picture/flash cards, worksheets, verbal questioning, and interactive use of counters). For each item the child 
answers correctly, they are given 1 point, summing to a total possible score of 65 . Raw total scores were used in analyses reported here. The TEMA has been well documented in the literature (e.g., Huntsinger et al., 1997; O'Hearn \& Landau, 2007; VanDerHeyden, Broussard, \& Cooley, 2006) and is statistically robust, with demonstrated internal reliability $(\alpha=.94)$ and test-retest reliability $(r=.94, p<.001)$.

Test of Early Reading Ability-Third Edition (TERA-3). The TERA-3, by Reid, Hresko, and Hammill (2001), assesses a child's early reading achievement with 80 items that capture knowledge of the alphabet, print conventions, and the ability to understand the meaning of printed script. Children receive 1 point for each correct answer they give, with a possible total score of 80 . Raw total scores were used in analyses reported here. The TERA-3 is designed for $3 \frac{1}{2}$ to $81 / 2$ year-olds and has been demonstrated to be statistically robust, with strong internal reliability $(\alpha=.95)$ and test-retest reliability $(r=.98, p<.001)$ with 4-6-year-olds (e.g., Harper \& Pelletier, 2008).

\subsection{Procedure}

An ethics application describing the methods of data collection was submitted and approved by the host institution, Victoria University of Wellington. Local preschools and kindergartens were approached in the suburbs of Wellington as locations of recruitment. Centres received NZ\$100 for their participation. Invitations to participate and permission forms were sent to parents, accompanied by the entire survey, which included demographic questions and the EASYC. The parent questionnaire was completed by one parent at home and mailed back to the researcher.

Following the parental completion of the questionnaire and receipt of signed informed consent, an interviewer spent a minimum of 30 minutes assessing literacy and numeracy in each child. Children completed the TERA and the TEMA individually in a quiet room at their respective childhood centre. One year later, the same participants were contacted to complete the same parent questionnaire and child tests.

\subsection{Data Analyses}

1) Raw correlations between EASYC items and concurrent TERA and TEMA scores were examined to determine which specific items were particularly highly correlated with numeracy and literacy outcomes, and to determine whether these items were particular in their associations with numeracy and literacy outcomes.

2) A factor analysis was performed on the 42 items of the EASYC to determine whether discriminable clusters of parental behaviours could be identified. We expected to find two broad groupings reflecting numeracy and literacy skill-building.

3) Multiple regressions were performed to identify which clusters of EASYC items significantly predicted child academic performance concurrently and longitudinally.

\section{Results}

\subsection{Correlations among EASYC Items and TERA and TEMA Scores}

For descriptive purposes, we correlated all individual EASYC items with the TERA and TEMA scores at T1 and T2 (see Table 1). The strongest two correlations were: 'our child asks how to spell words' with the TERA for Cohort 1 at T1 $(r=.52, p<.001)$ and 'trace or copy words on paper' with the TERA for Cohort 1 at T1 $(r=.45, p$ $<.001)$. Although a few items showed specificity in predicting numeracy vs. literacy, e.g., 'give our child maths challenges while traveling in the car' correlated .26, $p<.05$, with TEMA scores in Cohort 1 at T2, but only correlated $.02, n s$, with TERA scores at the same time, the general pattern noticeable in the correlation matrix was that most items correlated similarly with the literacy and numeracy outcomes. For example, Cohort 1 at T1 yielded similar correlations for 'practice writing his or her name' with both the TERA $(r=.41, p<.001)$ and the TEMA $(r$ $=.40, p<.001)$.

Another important take-away message from the correlation matrix was that some items displayed positive associations among younger children but negative associations among older children. For example, at T1 the 'assign our child words to copy' item yielded significant positive associations with both the TERA and TEMA for Cohort 1, but it yielded significant negative associations with both outcomes for Cohort 2 (children older by one year). The negative associations suggest that particular practices failed to benefit, and in fact might have detracted from, the appropriate development of literacy and numeracy skills at older ages.

Although the specific item correlations were illuminating about particular practices, we decided to simplify the data analyses by next conducting a factor analysis of the EASYC items to identify several general groupings of parental practices. 
Table 1. EASYC item correlations with TERA and TEMA

\begin{tabular}{|c|c|c|c|c|c|c|c|c|}
\hline \multirow{3}{*}{ EASYC Activity } & \multicolumn{4}{|c|}{ Time 1} & \multicolumn{4}{|c|}{ Time 2} \\
\hline & \multicolumn{2}{|c|}{ Cohort 1} & \multicolumn{2}{|c|}{ Cohort 2} & \multicolumn{2}{|c|}{ Cohort 1} & \multicolumn{2}{|c|}{ Cohort 2} \\
\hline & TERA & TEMA & TERA & TEMA & TERA & TEMA & TERA & TEMA \\
\hline Practice adding and subtracting single digit numbers & $.20 *$ & $.32 * *$ & .13 & $.27 * *$ & .23 & $.37 * *$ & $.31 * *$ & $.30 *$ \\
\hline Our child asks how to spell words & $.52 * *$ & $.46^{* *}$ & $.26 * *$ & $.25 *$ & $.44 * *$ & .21 & .07 & .04 \\
\hline Use maths in home routines e.g., Measuring ingredients for cooking & $.25 *$ & .19 & -.12 & -.15 & .15 & .07 & $.25 *$ & $.31 * *$ \\
\hline Play with maths-related board games and card games & .17 & $.24 *$ & .16 & $.26 * *$ & .13 & .24 & .06 & .21 \\
\hline Do art activities involving pattern or symmetry & $.22 *$ & .19 & -.06 & -.10 & .22 & .02 & .07 & -.01 \\
\hline Do maths-related workbooks or worksheets & $.22 *$ & -.01 & .13 & .15 & .04 & .12 & .23 & .18 \\
\hline Practice writing his or her name & $.41 * *$ & $.40 * *$ & -.09 & -.11 & .08 & -.08 & -.20 & -.15 \\
\hline Trace or copy words on paper & $.45^{* *}$ & $.34 * *$ & -.08 & -.06 & .23 & .01 & -.18 & -.23 \\
\hline Count actual objects or pictures & $.24 *$ & $.29 * *$ & -.04 & -.03 & .11 & .19 & .00 & -.08 \\
\hline Practice writing numerals & $.34 * *$ & $.26 * *$ & .17 & .19 & .16 & .11 & .05 & .09 \\
\hline Point out letters and words in the environment & .13 & .07 & $.20 *$ & $.23 *$ & .14 & .10 & -.02 & .07 \\
\hline Give our child maths challenges while travelling in the car & .00 & -.03 & .00 & .11 & .02 & $.26 *$ & .19 & $.28 *$ \\
\hline Buy our child workbooks or practice books & .13 & -.05 & .09 & .05 & .01 & .08 & $.27 *$ & .17 \\
\hline Tell our child that it is important to do well in school & -.19 & -.14 & -.09 & .06 & -.18 & -.23 & $.25 *$ & $.36^{* *}$ \\
\hline Use maths software on the computer & .07 & .05 & .17 & .12 & .11 & -.11 & $.28 *$ & $.41 * *$ \\
\hline Assign our child words to copy & $.32 * *$ & $.30 * *$ & $-.27 * *$ & $-.25 * *$ & .00 & -.15 & -.17 & -.12 \\
\hline Draw with crayons or markers & .16 & $.21 *$ & -.03 & -.10 & .11 & $-.26^{*}$ & .08 & -.08 \\
\hline Reading counting or shape books & $.21 *$ & .09 & -.04 & -.11 & -.17 & $-.28 *$ & $-.24 *$ & $-.31 *$ \\
\hline Play with blocks or construction toys & $-.31 * *$ & $-.24 *$ & .12 & .05 & -.15 & -.10 & -.08 & -.05 \\
\hline Do origami (paper folding) or cutting & .15 & .08 & -.15 & $-.20 *$ & -.05 & -.16 & -.06 & -.06 \\
\hline Play with maths toys i.e. Shape sorters, counting toys & -.03 & -.04 & -.11 & -.08 & -.02 & .01 & $-.30 *$ & $-.30 *$ \\
\hline Sing or listen to songs or finger plays that use maths e.g., Five little pumpkins & .17 & .06 & -.06 & -.12 & .10 & -.07 & -.23 & $-.27 *$ \\
\hline Teach our child to add small quantities by adding on his or her fingers & .16 & .13 & .11 & .03 & .09 & .05 & .06 & -.08 \\
\hline After reading part of a book, ask questions about the story & .02 & -.10 & -.10 & -.08 & -.01 & -.13 & -.11 & .03 \\
\hline Listen to stories read by a parent or grandparent & -.07 & -.03 & .16 & .02 & .04 & -.11 & -.05 & -.14 \\
\hline Have numbers depicted around the house, e.g., placemat, poster, pictures, calendar & .14 & .11 & .02 & .02 & .15 & .05 & -.14 & -.07 \\
\hline
\end{tabular}

Note: $* p<.05 . * * p<.01 . * * * p<.001$. 


\subsection{Factorial Structure of the EASYC}

In order to reduce the complexity of the large number of behaviours reported in the EASYC, a principal axis factoring (PAF) analysis with oblique rotation was performed. After considering all of the information available, the three-factor solution was adopted, and adequate Cronbach's alphas $(>.70)$ were obtained for all three factors. Table 2 reports the items that constituted these three factors at T1. The first factor was composed of 8 items that captured focused practice on writing and drawing and it was called "Writing practice". The second factor was composed of 13 items that described child involvement with "Games, stories, and puzzles". And the third factor constituted by 9 items described children's immersion in workbooks and other media, and it was named "Workbooks and software".

Table 2. EASYC (Encouragement of Academic Skills in Young Children) factor analysis item loadings at time 1

\begin{tabular}{|c|c|c|c|c|}
\hline & $\begin{array}{l}\text { Writing and drawing } \\
\text { practice }\end{array}$ & $\begin{array}{l}\text { Games, stories, } \\
\text { and puzzles }\end{array}$ & $\begin{array}{l}\text { Workbooks and } \\
\text { software }\end{array}$ & Cronbach's $\alpha$ \\
\hline Trace/copy words & .847 & & & .844 \\
\hline Asks how to spell words & .737 & & & \\
\hline Practice writing name & .681 & & & \\
\hline Practice writing numerals & .614 & & & \\
\hline Pattern or symmetry & .627 & & & \\
\hline Draw with crayons & .544 & & & \\
\hline Fold or cut paper & .450 & & & \\
\hline Assign words to copy & .375 & & & \\
\hline Read counting books & & .639 & & .834 \\
\hline Play made-up math games & & .663 & & \\
\hline Play with puzzles & & .559 & & \\
\hline Word-rhyming games & & .525 & & \\
\hline Math fingerplays and song & & .596 & & \\
\hline Use math in home routines & & .494 & & \\
\hline Count objects or pictures & & .486 & & \\
\hline Asks questions about story & & .420 & & \\
\hline Attend storytime & & .445 & & \\
\hline Point out words & & .389 & & \\
\hline Play with math toys & & .363 & & \\
\hline Read library books & & .351 & & \\
\hline Listen to stories & & .391 & & \\
\hline Proper letter formation & & & .585 & .761 \\
\hline Do math workbooks & & & .674 & \\
\hline Do alphabet workbooks & & & .572 & \\
\hline Bought workbooks & & & .510 & \\
\hline Use math software & & & .552 & \\
\hline Use pre-reading software & & & .471 & \\
\hline Math TV/videos & & & .346 & \\
\hline Math challenges & & & .357 & \\
\hline Play board and card games & & & .336 & \\
\hline
\end{tabular}

Note. All loadings $<.30$ were not reported above. 
Our prediction was that most items would fall clearly into either a literacy or numeracy factor, but the factor structure identified here did not support this prediction. Instead we found that all three factors presented a heterogeneous profile including both numeracy and literacy items. For example, the cluster named Games, stories, and puzzles included items like 'word-rhyming games' side-by-side with 'count objects or pictures'. Despite our expectation that we would obtain two reasonably homogeneous groupings of numeracy and literacy items, we obtained groupings based on activity type: a) practice writing, drawing, and tracing; b) games, stories, and puzzles; and c) workbooks and computer software.

\subsection{Did EASYC Factors Predict TERA and TEMA Scores?}

Regression analyses allowed us to determine whether the three EASYC factors significantly predicted concurrent or longitudinal literacy and numeracy scores. Expecting that we might find cohort differences, we conducted a moderation analysis in the following fashion: two hierarchical regressions were performed in which the TERA and TEMA scores were treated as the dependent variable separately, with variables added in three steps: cohort group; the three EASYC factors; and the interactions of cohort by each of the three EASYC factors.

TERA at T1 (Literacy). On the first step, cohort status explained significant variance as expected, i.e., older children performed better on the TERA. On the second step, only one of the three factors, namely Writing practice, yielded a significant relationship, $\beta=.17, p=.003$. Parents who encouraged children to practice writing and drawing had children who performed better on the literacy test of the TERA. And on the third step of the regression, the only significant interaction that was found was for Cohort $\mathrm{X}$ Writing practice, $\beta=-.95, p<.001$. The result was graphed with ModGraph (Jose, 2013), and Figure 1 was generated. The results show clearly that writing practice was positively related to TERA scores at T1 for the younger cohort (4-yr-olds), but not for the older cohort (5-yr-olds).

\section{Writing practice on TERA T1 Moderated by Cohort}

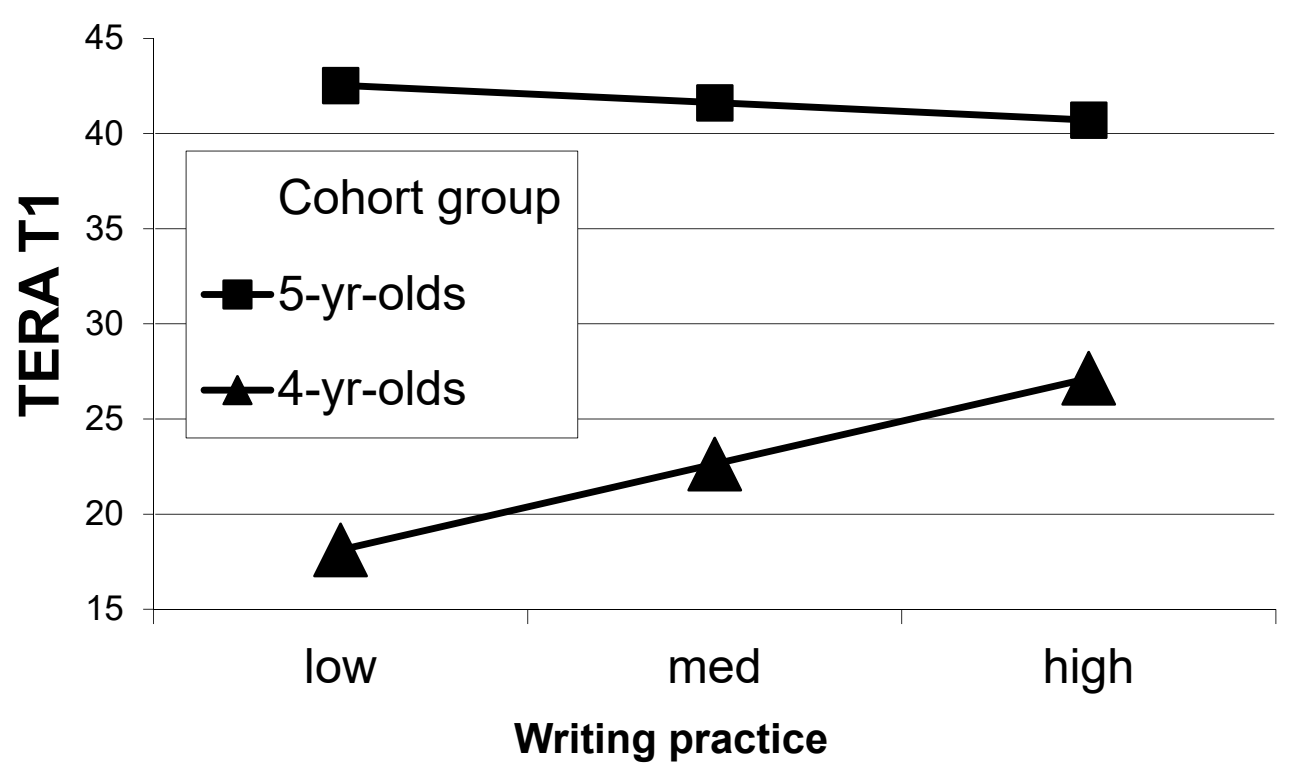

Figure 1. The relationship of writing practice with TERA (Test of Early Reading Ability) scores at T1 moderated by age cohort

TEMA at T1 (Mathematics). The same hierarchical regression was run for TEMA scores at T1, and a similar pattern of results was obtained. As with the TERA, older children performed better on the TEMA. On the second step, only one factor, namely Writing practice, yielded a significant relationship, $\beta=.19, p=.002$. Parents who encouraged children to practice writing and drawing had children who performed better on the numeracy test of the TEMA. And on the third step of the regression, the only significant interaction that was found was for Cohort $\mathrm{X}$ Writing practice, $\beta=-.95, p<.001$. The result was graphed and is presented as Figure 2 . The results show that writing practice was positively related to higher TEMA scores at $\mathrm{T} 1$ for the younger cohort (4-yr-olds), but not for 
the older cohort (5-yr-olds).

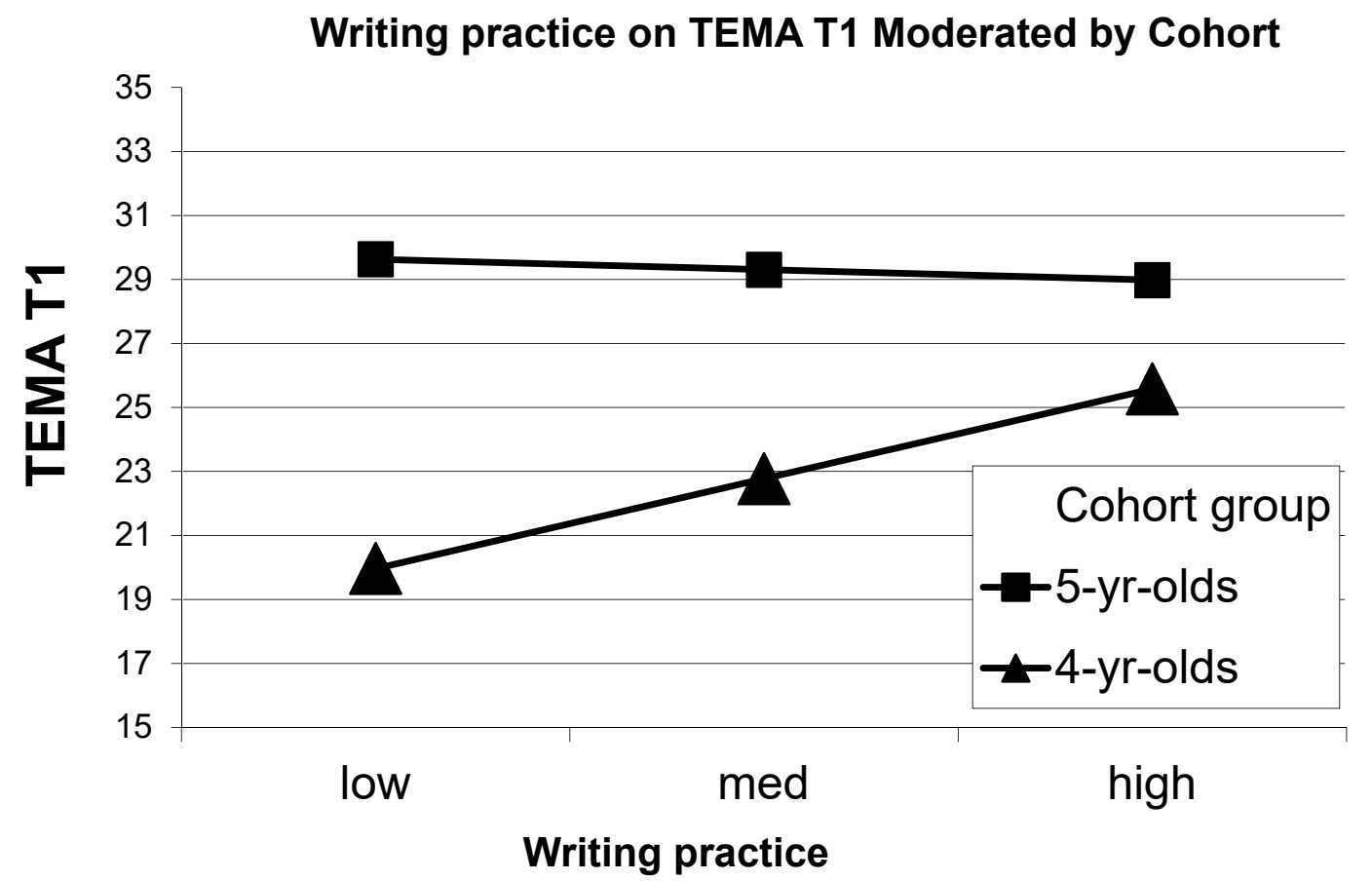

Figure 2. The relationship of writing practice with TEMA (Test of Early Mathematics Ability) scores at T1 moderated by age cohort

Impact of EASYC factors over time. The last analysis that we performed examined the possibility that higher levels of parental behaviours at T1 might have led to increases in either TERA or TEMA scores one year later. The same two regressions as described above were conducted with two differences: 1) TERA and TEMA scores at T2 were the two separate dependent variables; and 2) TERA or TEMA scores at T1 were entered in the first step of the regression in order to residualise the analysis on the respective score at $\mathrm{T} 2$.

In this analysis, writing practice was found to be a significant predictor of literacy (TERA) scores one year later, $\beta$ $=.13, p=.041$. No cohort moderation was evidenced on the third step. Thus, the finding suggests that parents who encouraged children to practice writing and drawing at $\mathrm{T} 1 \mathrm{had}$ children who performed better on the literacy test of the TERA one year later. In contrast, no significant predictor was found for the TEMA (mathematics).

\section{Discussion}

The results yielded several notable findings. First, at the EASYC item level, several specific parental practices were significantly associated with either or both numeracy and literacy skills. Second, a factor analysis of the items yielded three groups not rooted in the difference between numeracy and literacy but instead based on the types of activities in which parents engage. And third, among these three groupings of items, writing and drawing practices was the only factor found to be predictive of child academic performance concurrently and longitudinally one year later. These results provide an indication of the types of educational activities that are related to and predictive of New Zealand children's abilities in literacy and numeracy. Results showed the writing and drawing practices predicted increases in both TERA and TEMA scores concurrently for the younger cohort, but these practices predicted only TERA scores longitudinally. It is also notable that no clear differentiation between activities that were beneficial for numeracy and those beneficial for literacy was apparent in the data; therefore, the results concerning literacy and numeracy are discussed together below.

\subsection{Item-Level Associations with Literacy and Numeracy Outcomes}

Table 1 is illuminating in that it identifies some items that are beneficial for both literacy and numeracy outcomes (e.g., 'practice adding and subtracting single digit numbers'), some items that benefit only literacy (e.g., 'do art activities involving pattern or symmetry'), some items that benefit only numeracy (e.g., 'play with maths-related board games and card games'), and some items that did not benefit either numeracy or literacy (e.g., 'after reading 
part of a book, ask questions about the story'). This pattern suggests that the EASYC did a good job of capturing a wide range of activities that were differentially associated with literacy and numeracy skills. As noted above, most of the items seemed to be associated similarly with literacy and numeracy, in line with other research which reports that children in this age range do not show highly differentiated skills and proclivities between numeracy and literacy (Dulay et al., 2019; Napoli \& Purpura, 2018).

\subsection{Age-Specific Beneficial Activities for Young Children}

The present study identified a cluster of home-based activities which were positively related to academic skills for 4 -year-old children. Table 1 identified specific activities positively associated with TERA and TEMA scores for this youngest group. In particular, activities related to the literacy and numeracy abilities of 4-year-old children included: practicing writing their name; tracing or copying words on paper; asking about spelling; and practicing writing numerals. These activities focus on developing the fundamental skills required for competence in literacy, and appear to be linked to emergent literacy and early numeracy skills, such as letter naming, understanding the function of print, number naming, counting, and an understanding of quantity (Purpura, Hume, Sims, \& Lonigan, 2011; Sénéchal \& LeFevre, 2002; Sonnenschein \& Munsterman, 2002).

An important finding from the regression analyses was that Writing practice was beneficial to 4-year-olds, but the same activities for 5-year-olds were no longer beneficial. As the children became older, the activities associated with literacy and numeracy skills become more complex, and these foundational skills of practicing drawing proved not to be helpful one year later. For example, Table 1 reveals a group of five activities positively associated with numeracy and literacy outcomes for the oldest group (Cohort 2 at T1): 'use maths in home routines', 'give our child maths challenges while traveling in the car', 'buy our child workbooks or practice books', 'tell our child that it is important to do well in school', and 'use maths software on the computer'.

These age-specific results suggest that, as children grow older, higher-level activities are necessary for their continued learning and development (Bodrova \& Leong, 1996). Activities and environments to which parents expose their children need to evolve to meet the rapidly changing needs of their child. This view is congruent with Vygotskian theory and previous research which shows that preschool learning and development is enhanced through exposing children to activities and education programmes that are appropriately matched to the individual child's ZPD and that address the child's specific needs (Bodrova \& Leong, 1996; Howes et al., 2008). If in-home help and support is going to be beneficial to learning outcomes for children, parents need to be aware that as their child ages, particularly as they reach formal schooling at age 5 or 6 , they will require more challenging tasks which stimulate their developing academic ability and are appropriate to their individual needs.

\subsection{Limitations of the Present Study and Future Directions}

Overall, a greater number of significant relationships were found for the youngest children's (4-year-olds') numeracy and literacy test results compared with the older children. The reasons for the uneven ability of the EASYC to predict academic outcomes over children's ages warrant further investigation and possible modification of the measure. As the research basis for this tool was initially conducted in the United States (Huntsinger et al., 2016), it is possible that the measure has not adequately captured the full range of activities New Zealand parents use with their children. Future work in different countries should be preceded by qualitative research to identify unique local educational experiences. Also, it appears that the activities measured were more relevant for use with children before they reach school age, and items which support 5 to 6 -year-olds were not captured adequately by the measure. It is also acknowledged that the measure does not capture all possible activities that parents choose to do with their children, however, the measure seems to be of reasonable length and captures a wide range of possible types of activities. Still, it must be noted that a limitation of the measure is that it may not include some critical activities that would be predictive of young children's literacy and numeracy. We also saw a relatively large attrition rate in our longitudinal study from $\mathrm{T} 1$ to $\mathrm{T} 2$; future work should confirm developmental patterns with less attrition.

The current study also fails to capture the functioning of all cultural groups within New Zealand, as the sample was not representative of minority groups (including Māori, Pasifika and Asian cultures). It is highly likely that parents within these minority groups use a range of educational activities in their home environments that are not captured in the EASYC. Further study is required to fully understand the activities most beneficial for children across all of New Zealand. Further, the processes under study here should be investigated in other national and cultural settings around the world because it is likely that each setting will manifest unique techniques to teach language and number knowledge.

And last, the data reported here were collected before the COVID-19 pandemic impacted family and school 
experiences. Future work may seek investigate how lock-down conditions (e.g., young children being largely restricted to the home situation as opposed to visiting museums and public settings) might have positively and negatively influenced at-home educational activities conducted by parents with children.

\section{Conclusions}

In summary, the findings of the present study identified certain types of helpful activities parents use at home to encourage literacy and numeracy development in young children and to foster school readiness. On the basis of our results, we would recommend that parents encourage both basic addition and subtraction practice and general writing and drawing practice, as they were both related to academic ability across different ages. Many of the activities related to child academic abilities changed as the children grew older, highlighting the importance of choosing at-home activities to match and challenge the child's ever-changing developmental abilities. The current results provide a good starting point for identifying and understanding in-home activities which effectively support children as they begin formal education.

\section{References}

Aunola, K., Leskinen, E., Lerkkanen, M., \& Nurmi, J. (2004). Developmental dynamics of math performance from preschool to grade 2. Journal of Educational Psychology, 96(4), 699-713. https://doi.org/10.1037/0022-0663.96.4.699

Baroody, A. J. (1987). Children's mathematical thinking: A developmental framework for preschool, primary, and special education teachers. New York, NY: Teachers College Press.

Blevins-Knabe, B., \& Musun-Miller, L. (1996). Number use at home by children and their parents and its relationship to early mathematical performance. Early Development and Parenting, 5(1), 35-45. https://doi.org/10.1037/0022-0663.96.4.699

Bodrova, E. \& Leong, D. J. (1996). Tools of the mind: The Vygotskian approach to early childhood education. Upper Saddle River, NJ: Merrill Prentice-Hall.

Claessens, A., Duncan, G., \& Engel, M. (2009). Kindergarten skills and fifth-grade achievement: Evidence from the ECLS-K. Economics of Education Review, 28(4), 415. https://doi.org/10.1016/j.econedurev.2008.09.003

Dulay, K. M., Cheung, S. K., Reyes, P., \& McBride, C. (2019). Effects of parent coaching on Filipino children's numeracy, language, and literacy skills. Journal of Educational Psychology, 111(4), 641-662. https://doi.org/10.1037/edu0000315

Duncan, G. J., Dowsett, C. J., Claessens, A., Magnuson, K., Huston, A. C., Klebanov, P., \& Japel, C. (2007). School readiness and later achievement. Developmental Psychology, 43(6), 1428-1446. https://doi.org/10.1037/0012-1649.43.6.1428

Ginsburg, H., \& Baroody, A. (1990). Test of Early Mathematics Ability-2. Austin, TX: Pro-Ed.

Griffin, E. A., \& Morrison, F. J. (1997). The unique contribution of home literacy environment to differences in early literacy skills. Early Child Development and Care, 127(1), 233-243. https://doi.org/10.1080/0300443971270119

Harper, S. N., \& Pelletier, J. P. (2008). Gender and language issues in assessing early literacy: Group differences in children's performance on the test of early reading ability. Journal of Psychoeducational Assessment, 26(2), 185-194. https://doi.org/ 10.1177/0734282908314105

Howes, C., Burchinal, M., Pianta, R., Bryant, D., Early, D., Clifford, R., \& Barbarin, O. (2008). Ready to learn? Children's pre-academic achievement in pre-Kindergarten programs. Early Childhood Research Quarterly, 23(1), 27-50. https://doi.org/10.1016/j.ecresq.2007.05.002

Hood, M., Conlon, E., \& Andrews, G. (2008). Preschool home literacy practices and children's literacy development: A longitudinal analysis. Journal of Educational Psychology, 100(2), 252-271. https://doi.org/10.1037/0022-0663.100.2.252

Hooper, S. R., Roberts, J., Sideris, J., Burchinal, M., \& Zeisel, S. (2010). Longitudinal predictors of reading and math trajectories through middle school for African American versus Caucasian students across two samples. Developmental Psychology, 46(5), 1018-1029. https://doi.org/10.1037/a0018877

Huntsinger, C. S., Jose, P. E., \& Larson, S. L. (1998). Do parent practices to encourage academic competence influence the social adjustment of young European American and Chinese American children? Developmental Psychology, 34, 747-756. https://doi.org/10.1037/0012-1649.34.4.747 
Huntsinger, C. S., Jose, P. E., Larson, S. L., Balsink Krieg, D., \& Shaligram, C. (2000). Mathematics, vocabulary, and reading development in Chinese-American and European-American children over the primary school years. Journal of Educational Psychology, 92, 745-760. https://doi.org/10.1037//0022-0663.92.4.745

Huntsinger, C. S., Jose, P. E., Liaw, F., \& Ching, W. (1997). Cultural differences in early mathematics learning: A comparison of Euro-American, Chinese-American, and Taiwan Chinese families. International Journal of Behavioural Development, 21, 371-388. https://doi.org/10.1080/016502597384929

Huntsinger, C. S., Jose, P. E. \& Luo, Z. (2016). Parental facilitation of early mathematics and reading skills and knowledge through encouragement of home-based activities. Early Childhood Research Quarterly, 37(4), 1-15. https://doi.org/10.1016/j.ecresq.2016.02.005

Jose, P. E. (2013). ModGraph-I: A programme to compute cell means for the graphical display of moderational analyses: The internet version, Version 3.0. Victoria University of Wellington, Wellington, New Zealand. Retrieved November 24, 2014, from http://pavlov.psyc.vuw.ac.nz/paul-jose/modgraph/

Kara, H. G. E. (2019). Okul oncesi dönemde cocuğa evde sunulan desteğin okuma yazmaya hazırlık ve matematik becerileri bağlamında incelenmesi. Bayburt Ĕgitim Fakültesi Dergisi, 14(27), 87-105. https://doi.org/10.35675/befdergi.422261

Kara, H. G. E., \& Çoksoyluer, S. K. (2017). Encouragement of early academic skills at home during early childhood period: Validity and reliability study of the EASYC scale. Universal Journal of Educational Research, 5(12), 2294-2303. https://doi.org/10.13189/ujer.2017.051220

Labour Market Statistics. (2018). Labour market statistics (income): June 2018 quarter. Retrieved Dec 3, 2019, from https://www.stats.govt.nz/information-releases/labour-market-statistics-income-june-2018-quarter

Ladd, G. W., \& Dinella, L. M. (2009). Continuity and change in early school engagement: Predictive of children's achievement trajectories from first to eighth grade? Journal of Educational Psychology, 101(1), 190-206. https://doi.org/10.1037/a0013153

Lehrl, S., Ebert, S., Blaurock, S., Rossbach, H-G., \& Weinert, S. (2020). Long-term and domain-specific relations between the early years home learning environment and students' academic outcomes in secondary school. School Effectiveness and School Improvement, 31(1), 102-124. https://doi.org/10.1080/09243453.2019.1618346

Lehrl, S., Smidt, W., Grosse, C., \& Richter, D. (2014). Patterns of literacy and numeracy activities in preschool and their relation to structural characteristics and children's home activities. Research Papers in Education, 29(5), 577-597. https://doi.org/10.1080/02671522.2013.792865

Lonigan, C. J., Burgess, S. R., \& Anthony, J. L. (2000). Development of emergent literacy and early reading skills in preschool children: Evidence from a latent variable longitudinal study. Developmental Psychology, 36(5), 596-613. Retrieved from https://doi.org/10.1037//OOI2-1649.36.5.596

Napoli, A. R., \& Purpura, D. J. (2018). The home literacy and numeracy environment in preschool: Cross-domain relations of parent-child practices and child outcomes. Journal of Experimental Child Psychology, 166, 581-603. https://doi.org/10.1016/j.jecp.2017.10.002

O'Hearn, K., \& Landau, B. (2007). Mathematical skill in individuals with Williams syndrome: Evidence from a standardized mathematics battery. Brain and Cognition, 64(3), 238-246.

Pagani, L. S., Fitzpatrick, C., Archambault, I., \& Janosz, M. (2010). School readiness and later achievement: A French Canadian replication and extension. Developmental Psychology, 46(5), 984-994. https://doi.org/10.1037/a0018881

Purpura, D. J., Hume, L. E., Sims, D. M., \& Lonigan, C. J. (2011). Early literacy and early numeracy: The value of including early literacy skills in the prediction of numeracy development. Journal of Experimental Child Psychology, 111(4), 647-658. https://doi.org/10.35675/befdergi.422261

Reid, D. K., Hresko, W. P., \& Hammill, D. D. (2001). Test of Early Reading Ability-3. Austin, TX: Pro-Ed.

Romano, E., Babchishin, L., Pagani, L. S., \& Kohen, D. (2010). School readiness and later achievement: Replication and extension using a nationwide Canadian survey. Developmental Psychology, 46(5), 995-1007. https://doi.org/10.1037/a0018880

Sénéchal, M., Pagan, S., Lever, R., \& Ouellette, G. P. (2008). Relations among the frequency of shared reading and 4-year-old children's vocabulary, morphological and syntax comprehension, and narrative skills. Early 
Education and Development, 19(1), 27-44. https://doi.org/10.35675/befdergi.422261

Sénéchal, M., \& LeFevre, J. A. (2002). Parental involvement in the development of children's reading skill: A five-year longitudinal study. Child Development, 73, 445-460. https://doi.org/ 10.1016/j.jecp.2013.11.006

Sonnenschein, S., \& Munsterman, K. (2002). The influence of home-based reading interactions on 5-year-olds' reading motivations and early literacy development. Early Childhood Research Quarterly, 17, 318-337.

Skwarchuk, S., Sowinski, C., \& LeFevre, J. (2014). Formal and informal home learning activities in relation to children's early numeracy and literacy skills: The development of a home numeracy model. Journal of Experimental Child Psychology, 121, 63-84. https://doi.org/10.1016/j.jecp.2013.11.006

Vadeboncoeur, J. A., \& Dalkili, M. (2019). Playing at, participating in, and transforming cultures: A Vygotskian perspective on the potential of early childhoods. In D. Whitebread, V. Grau, K. Kumpulainen, M. McClelland, N. Perry, \& D. Pino-Pasternak (Eds.), The Sage handbook of developmental psychology and early childhood education (pp. 223-238). Los Angeles: Sage Publications.

VanDerHeyden, A. M., Broussard, C., \& Cooley, A. (2006). Further development of measures of early math performance for preschoolers. Journal of School Psychology, 44(6) 533-553, https://doi.org/10.1016/j.jsp.2006.07.003

Vygotsky, L. S. (1978). Mind in society: The development of higher psychological processes. Cambridge, MA: Harvard University Press.

\section{Copyrights}

Copyright for this article is retained by the author(s), with first publication rights granted to the journal.

This is an open-access article distributed under the terms and conditions of the Creative Commons Attribution license (http://creativecommons.org/licenses/by/4.0/). 